\title{
HUBUNGAN FAKTOR REPRODUKSI DENGAN KEJADIAN KANKER PAYUDARA PADA WANITA DI RSUP DR. M. DJAMIL PADANG
}

\author{
Relationship Between Reproductive Factors and Breast Cancer Events \\ in Women in dr. M. Djamil Padang
}

\author{
Sukmayenti $^{1}$, Nirmala Sari $^{2}$ \\ ${ }^{1,2}$ Dosen Tetap Jurusan Kebidanan Universitas Baiturrahmah Padang \\ Email: sukmayenti@yahoo.com
}

\begin{abstract}
Abstrak
Kanker payudara termasuk penyakit yang tidak menular, saat ini menjadi masalah kesehatan utama baik di dunia maupun di Indonesia. Angka insidensi kanker payudara di yakini berkaitan dengan beberapa faktor resiko. Penelitian ini bertujuan untuk mengetahui hubungan faktor reproduksi (usia menarche, paritas dan riwayat menyusui) dengan kejadian kanker payudara pada wanita. Penelitian case control dilakukan di RSUP DR. M. Djamil Padang dengan analisis secara univariat dan bivariat menggunakan uji Chi-square. Dari 72 orang sampel (36 orang kasus dan 36 orang control) diketahui bahwa responden dengan usia menarche berisiko 80,6\% pada kelompok kasus dan 19,4\% pada kelompok kontrol, responden dengan paritas berisiko sebesar 33,3\% pada kelompok kasus dan 66,7\% pada kelompok control, responden dengan riwayat menyusui beresiko sebesar $65,6 \%$ pada kelompok kasus dan $34,4 \%$ pada kelompok kontrol. Ada hubungan antara usia menarche dan riwayat menyusui dengan kejadian kanker payudara. Tidak ada hubungan antara paritas dengan kejadian kanker payudara. Perkuat upaya promosi kesehatan sebagai upaya pencegahan kanker payudara.
\end{abstract}

Kata Kunci: Faktor reproduksi, Kanker Payudara

\begin{abstract}
Breast cancer is a non-contagious disease, currently a major health problem both in the world and in Indonesia. The incidence of breast cancer is believed to be related to several risk factors. This study aims to determine the relationship of reproductive factors (age of menarche, parity and history of breastfeeding) with the incidence of breast cancer in women. Case control research was carried out at DR. M. Djamil Padang with univariate and bivariate analysis using Chi-square test. Of the 72 samples (36 cases and 36 controls) it was found that respondents with menarche age were $80.6 \%$ at risk in the case group and $19.4 \%$ in the control group, respondents with risk parity were $33.3 \%$ in the case group and 66 , $7 \%$ in the control group, respondents with a breastfeeding history were at risk of $65.6 \%$ in the case group and $34.4 \%$ in the control group. There is a relationship between age of menarche and history of breastfeeding with the incidence of breast cancer. There is no relationship between parity and the incidence of breast cancer. Strengthen health promotion efforts as an effort to prevent breast cancer.
\end{abstract}

Keywords: Reproductive factors, breast cancer

\section{PENDAHULUAN}

Kanker payudara termasuk penyakit yang tidak menular, saat ini menjadi masalah kesehatan utama baik di dunia maupun di Indonesia. Menurut Word Health Organization (WHO) tahun 2012, kejadian kanker payudara sebanyak 1.677.000 kasus. Kanker payudara merupakan kanker yang paling banyak di derita oleh kaum wanita. Diperkirakan jumlah kasus baru tidak kurang dari 1.050.346 pertahun. Berdasarkan estimasi International Agency for Research of Cancer, pada tahun 2020 akan ada 1,15 juta kasus baru dan $55 \%$ kematian diprediksi terjadi di negara berkembang. Data International Union Against Cancer (UICC) dari WHO tahun 2009 menunjukan setiap tahun 12 juta orang diseluruh dunia menderita kanker dan 7,6 juta diantaranya meninggal dunia. Jika tidak diambil tindakan pengendalian yang memadai, maka pada tahun 2030 diperkirakan 26 juta orang akan menderita kanker dan 17 juta diantaranya akan meninggal dunia. Kejadian ini akan lebih cepat di daerah miskin dan berkembang.

Prevalensi penyakit kanker di Indonesia cukup tinggi. Berdasarkan data Riset Kesehatan Dasar (Riskesdas) tahun 2013, prevelensi tumor/kanker di Indonesia 
adalah 1,4 per 1000 penduduk atau sekitar 330.000 orang. Kanker payudara termasuk kanker tertinggi pada wanita di Indonesia. Kejadian kanker di provinsi Sumatera Barat $(5,6 \%)$ lebih tinggi dari rata-rata nasional $(4,3 \%)$, yaitu pada urutan tertinggi ke 6 dari 33 provinsi di Indonesia berdasarkan Riskesdas Nasional tahun 2008

Berdasarkan data yang diperoleh dari Medical Record RSUP Dr. M. Djamil Padang penderita kanker payudara yang melakukan rawat jalan sebanyak 2082 orang pada tahun 2014, 972 orang di tahun 2015, naik menjadi 4132 orang di tahun 2016, dan 1941 orang pada tahun 2017. Sedangkan penderita kanker payudara yang rawat inap sebanyak 241 orang tahun 2014, 155 orang tahun 2015, 109 orang pada tahun 2016 dan 165 orang di tahun 2017.

Angka insidensi kanker payudara yang selalu meningkat di yakini berkaitan dengan peningkatan risiko untuk terjadinya kanker payudara. Setiap risiko kanker payudara pada wanita dapat mempunyai probabilitas yang lebih tinggi atau lebih rendah, tergantung pada beberapa faktor, yang meliputi faktor reproduksi (Usia menarche dini, kehamilan pertama pada usia lanjut, paritas yang rendah, masa laktasi), faktor endokrin (kontrasepsi oral, terapi sulih hormon), faktor diet (obesitas, konsumsi alkohol), dan faktor genetik (anggota keluarga dengan kanker payudara, riwayat keluarga dengan kanker ovarium). ${ }^{18}$

Menurut Putra, S.R (2015) spesifik kanker payudara masih belum diketahui. Tetapi terdapat banyak faktor yang diperkirakan mempunyai pengaruh terhadap tingginya kejadian kanker payudara, faktor tersebut diantaranya seperti: obesitas (kegemukan), perokok berat, pecandu alkohol, diet atau pola makan tidak sehat, kurang olahraga, genetik, usia, hormonal, riwayat menyusui, riwayat kehamilan (paritas) dan riwayat haid (menarche). Sementara menurut Mulyani, N.S. (2013) faktor yang mempengaruhi kejadian kanker payudara adalah: faktor usia, faktor genetik, penggunaan hormon estrogen, penggunaan pil $\mathrm{KB}$, usia menarche dan riwayat kanker payudara.
Usia menstruasi pertama (menarche) pada usia kurang dari 12 tahun memiliki resiko 1,7 hingga 3,4 kali lebih besar daripada wanita dengan menarche yang datang pada usia lebih dari 12 tahun (Olfah, 2013). Wanita yang melahirkan baru sekali (setelah usia 30 tahun) atau yang belum pernah melahirkan (nulipara) memiliki resiko lebih besar dari pada yang melahirkan anak pertama di usia 20 tahun. ${ }^{22}$ Wanita yang tidak pernah menyusui akan memiliki resiko 2,118 kali lebih tinggi untuk mengalami kanker payudara dibandingkan wanita yang pernah menyusui. Hal ini sesuai dengan hasil penelitian Ellison (2007) yang menemukan bahwa menyusui dapat mengurangi resiko kanker payudara pada wanita dan secara alami mengurangi resiko kanker payudara sebesar 59\%. ${ }^{17}$

Berdasarkan fenomena diatas maka tujuan penelitian ini adalah Hubungan Faktor Reproduksi dengan Kejadian Kanker Payudara pada Wanita di RSUP Dr. M.Djamil Padang Tahun 2018.

\section{METODE PENELITIAN}

Penelitian ini bersifat analitik
dengan desain case control, untuk
mengetahui hubungan faktor reproduksi
dengan kejadian kanker payudara pada
wanita. Penelitian dilakukan di poli bedah
RSUP Dr. M. Djamil Padang pada tahun
2018, data dikumpulkan dengan wawancara
oleh peneliti menggunakan kuesioner. Data
di analisis secara univariat dan bivariat
dengan menggunakan uji chi square.
Populasi kasus dalam penelitian ini
adalah wanita yang terdiagnosis kanker
payudara yang rawat jalan di poli bedah di
RSUP Dr. M. Djamil Padang, dan populasi
controlnya adalah wanita yang tidak
terdiagnosis kanker payudara. Jumlah
sampel sebanyak 36 orang kasus dan 36
orang control (1:1) yang ditentukan
berdasarkan rumus Alimul (2010). sampel
dipilih dengan teknik accidental sampling.

\section{HASIL}

Berdasarkan penelitian yang telah dilakukan, didapatkan hasil penelitian sebagai berikut: 
1. Usia Menarche

Tabel 1.1 Distribusi Frekuensi Responden Berdasarkan Usia Menarche di RSUP Dr. M. Djamil Padang Tahun 2018

\begin{tabular}{lllll}
\hline & \multicolumn{2}{l}{ Kasus } & \multicolumn{2}{c}{ Kontrol } \\
\cline { 2 - 5 } $\begin{array}{l}\text { Usia } \\
\text { Menarche }\end{array}$ & f & \% & f & \% \\
\hline Berisiko & 29 & 80,6 & 7 & 19,4 \\
\hline $\begin{array}{l}\text { Tidak } \\
\text { Berisiko }\end{array}$ & 7 & 19,4 & 29 & 80,6 \\
\hline
\end{tabular}

Berdasarkan tabel 1.1 diketahui bahwa responden dengan usia menarche berisiko $80,6 \%$ pada kelompok kasus dan $19,4 \%$ pada kelompok kontrol.

\section{Paritas}

Tabel 1.2 Distribusi Frekuensi Responden Berdasarkan Paritas di RSUP Dr. M. Djamil Padang

\begin{tabular}{lllll}
\hline Paritas & \multicolumn{2}{l}{ Kasus } & \multicolumn{2}{c}{ Kontrol } \\
\cline { 2 - 5 } & f & \% & f & \% \\
\hline Berisiko & 3 & 33,3 & 6 & 66,7 \\
Tidak & 33 & 52,4 & 30 & 47,6 \\
Berisiko & & & & \\
\hline
\end{tabular}

Berdasarkan tabel 1.2 diketahui bahwa responden dengan paritas berisiko sebesar 33,3\% pada kelompok kasus dan $66,7 \%$ pada kelompok kontrol.

3. Riwayat Menyusui

Tabel 1.3 Distribusi Frekuensi Responden Berdasarkan Riwayat Menyusui di RSUP Dr. M. Djamil Padang

\begin{tabular}{lrrrr}
\hline Riwayat & \multicolumn{2}{c}{ Kasus } & \multicolumn{2}{c}{ Kontrol } \\
\cline { 2 - 5 } Menyusui & f & \% & f & \% \\
\hline Berisiko & 21 & 65,6 & 11 & 34,4 \\
Tidak & 15 & 37,5 & 25 & 62,5 \\
Berisiko & & & & \\
\hline
\end{tabular}

Berdasarkan tabel 5.6 diketahui bahwa responden dengan riwayat menyusui sebesar $65,6 \%$ pada kelompok kasus dan $34,4 \%$ pada kelompok kontrol.

4. Hubungan Usia Menarche dengan Kejadian Kanker Payudara

Tabel 1.4 Hubungan Usia Menarche dengan Kejadian Kanker Payudara

\begin{tabular}{lllllll}
\hline Usia & \multicolumn{2}{l}{ Kasus } & \multicolumn{2}{c}{ Kontrol } & $P$ & Odd \\
\cline { 2 - 4 } $\begin{array}{l}\text { Menarc } \\
\text { he }\end{array}$ & f & $\%$ & f & $\%$ & $V$ & $s$ \\
& & & & $a l$ & Rati \\
\hline
\end{tabular}

\begin{tabular}{lllllll}
\hline & & & \multicolumn{3}{c}{ ue } & o \\
\hline Berisiko & 29 & 80,6 & 7 & 19,4 & & \\
\hline Tidak & 7 & 19,4 & 29 & 80,6 & 0, & 26,8 \\
Berisiko & & & & \multicolumn{2}{c}{00} & \\
\multicolumn{3}{r}{ Berdasarkan } & tabel & 1.4 & diketahui
\end{tabular}
bahwa usia menarche dengan kategori berisiko lebih banyak pada kelompok kasus $(80,6 \%)$ dibanding kelompok kontrol $(19,4 \%)$. Dari hasil uji statistik diketahui nilai $\mathrm{p}<0,05(0,000)$ dan odds ratio 26,8. Berarti ada hubungan usia menarche dengan kejadian kanker payudara, dimana responden dengan usia menarche berisiko mempunyai kecenderungan 27 kali untuk terkena kanker payudara dibanding responden dengan usia kategori risiko rendah.

5. Hubungan Paritas dengan Kejadian Kanker Payudara

Tabel 1.5 Hubungan Paritas dengan Kejadian Kanker Payudara

\begin{tabular}{|c|c|c|c|c|c|c|}
\hline \multirow[b]{2}{*}{ Paritas } & \multicolumn{2}{|c|}{ Kasus } & \multicolumn{2}{|c|}{ Kontrol } & \multirow{2}{*}{$\begin{array}{l}P \\
\text { Val } \\
\text { ue }\end{array}$} & \multirow{2}{*}{$\begin{array}{l}\text { Odds } \\
\text { Rati } \\
\text { o }\end{array}$} \\
\hline & f & $\%$ & $\mathbf{f}$ & $\%$ & & \\
\hline Berisiko & 3 & 33,3 & 6 & 66,7 & & \\
\hline $\begin{array}{l}\text { Tidak } \\
\text { Berisiko }\end{array}$ & 33 & 52,4 & 30 & 47,6 & 0,476 & 1,1 \\
\hline
\end{tabular}

Berdasarkan tabel 1.5 diketahui bahwa paritas berisiko lebih banyak pada kelompok kontrol $(66,7)$ dibanding kelompok kasus (33,3\%). Dari hasil uji statistik diketahui nilai $\mathrm{p}>0,05(0,476)$ dan odds ratio 0,4. Berarti tidak ada hubungan paritas dengan kejadian kanker payudara, dimana responden dengan paritas berisiko cuma punya kecendrungan 0,4 kali terkena kanker payudara dibanding responden dengan paritas tidak berisiko.

6. Hubungan Riwayat Menyusui dengan Kejadian Kanker Payudara

Tabel 1.6 Hubungan Riwayat Menyusui dengan Kejadian Kanker Payudara

\begin{tabular}{|c|c|c|c|c|c|c|}
\hline \multirow{2}{*}{$\begin{array}{l}\text { Riwayat } \\
\text { Menyu- } \\
\text { sui }\end{array}$} & \multicolumn{2}{|c|}{ Kasus } & \multicolumn{2}{|c|}{ Kontrol } & \multirow{2}{*}{$\begin{array}{l}P \\
\text { Val } \\
\text { ue }\end{array}$} & \multirow{2}{*}{$\begin{array}{l}\text { Odd } \\
s \\
\text { Rati } \\
o\end{array}$} \\
\hline & $\mathbf{f}$ & $\%$ & $\mathbf{f}$ & $\%$ & & \\
\hline Berisiko & 21 & 65,6 & 11 & 34,4 & & \\
\hline Tidak & 15 & 37,5 & 25 & 62,5 & 0,033 & 5,6 \\
\hline
\end{tabular}


Berisiko

Berdasarkan tabel 1.6 diketahui

bahwa riwayat menyusui dengan kategori berisiko lebih banyak pada kelompok kasus $(65,6 \%)$ dibanding kelompok kontrol $(34,4 \%)$. Dari hasil uji statistik diketahui nilai $\mathrm{p}<0,05(0,033)$ dan odds ratio 5,6. Berarti ada hubungan riwayat menyusui dengan kejadian kanker payudara, dimana responden dengan riwayat menyusui berisiko mempunyai kecenderungan 5,6 kali terkena kanker payudara dibanding responden dengan riwayat menyusui tidak berisiko.

\section{PEMBAHASAN}

\section{Hubungan Usia Menarche dengan} Kejadian Kanker Payudara

Hasil penelitian menyatakan ada hubungan usia menarche dengan kejadian kanker payudara, dimana responden dengan usia menarche berisiko mempunyai kecenderungan 27 kali untuk terkena kanker payudara dibanding responden dengan usia kategori risiko rendah. Perempuan yang pertama kali mengalami haid lebih awal (sebelum usia 12 tahun) atau mengalami menopause setelah usia 55 tahun memiliki risiko terkena kanker payudara lebih tinggi. Menurut Siti (2013) jika seorang wanita mengalami menstruasi di usia dini (sebelum 12 tahun) akan memiliki peningkatan risiko kanker payudara, karena semakin cepat seorang wanita mengalami pubertas maka semakin panjang waktu terpaparnya jaringan payudaranya oleh unsur-unsur berbahaya yang menyebabkan kanker seperti bahan kimia, estrogen, ataupun radiasi.yang berpengaruh terhadap proses proliferasi jaringan termasuk jaringan payudara.

Menarche awal juga akan menyebabkan banyaknya jumlah siklus haid dan penutupan estrogen yang berulang ulang dan mempunyai efek rangsangan terhadap epitel mammae sehingga meningkatkan kemungkinan abnormalitas jaringan payudara (Tapan, 2005).

Simpulan, semakin awal seseorang mengalami menarche maka semakin meningkat risiko untuk terjadinya kanker payudara.

\section{Hubungan Paritas dengan Kejadian Kanker Payudara}

Hasil penelitian menyatakan tidak ada hubungan paritas dengan kejadian kanker payudara. Hasil penelitian ini berbeda dengan hasil penelitian yang dilakukan oleh Priyatin, dkk yang berjudul Faktor Risiko yang Berpengaruh Terhadap Kejadian Kanker Payudara di RSUP DR. Kariadi Semarang dengan hasil analisis statistik didapatkan nilai $\mathrm{OR}=4,353$ dan CI $95 \%=0,463-40,898$. Hasil analisis tersebut menunjukkan bahwa OR > $1=4,353$ yang berarti paritas berisiko dapat mempertinggi kejadian kanker payudara.

Efek dari paritas (banyaknya melahirkan) terhadap jumlah risiko kanker payudara telah lama diteliti. Dalam suatu studi metaanalisis, dilaporkan bahwa wanita yang melahirkan sekali mempunyai risiko $30 \%$ untuk berkembang menjadi kanker dibandingkaan dengan wanita yang multipara (melahirkan lebih dari sekali).

Paritas yang dimaksud adalah berapa jumlah anak dimiliki oleh responden. Paritas dikelompokkan menjadi 2 kategori yaitu, tidak memiliki anak (nulipara) atau punya satu anak (primipara) dan punya anak lebih dari dua (multipara). Wanita yang tidak mempunyai anak tidak pernah menyusui, sementara wanita yang menyusui kadar estrogen dan progesteron akan tetap rendah selama menyusui sehingga mengurangi pengaruh hormon tersebut terhadap proliferasi jaringan termasuk jaringan payudara. Berdasarkan hasil penelitian terdapat responden yang memiliki usia berisiko namun belum menikah dan ada yang tidak memiliki anak.

\section{Hubungan Riwayat Menyusui dengan Kejadian Kanker Payudara}

Hasil penelitian menyatakan ada hubungan riwayat menyusui dengan kejadian kanker payudara, dimana responden dengan riwayat menyusui berisiko mempunyai kecenderungan 5,6 kali terkena kanker payudara dibanding responden dengan riwayat menyusui tidak berisiko.

Penelitian ini sama dengan penelitian yang dilakukan oleh Priyatin, dkk yang 
berjudul Faktor Risiko yang Berpengaruh Terhadap Kejadian Kanker Payudara di RSUP DR. Kariadi Semarang dengan hasil analisis statistik didapatkan nilai $\mathrm{OR}=2,118$ dan CI 95\% = 0,364 - 12,320. OR > $1=$ 2,118 yang dapat mempertinggi risiko kanker payudara pada ibu yang tidak pernah menyusui ataupun yang menyusui $<2$ tahun. Menyusui dapat mempengaruhi tingkat estrogen dalam tubuh wanita, yang mana hormon estrogen pada wanita adalah bahan utama penyebab kanker payudara. Menyusui dapat menurunkan kadar estrogen, karena itu risiko seorang wanita menderita kanker payudara akan menurun setiap kali wanita hamil dan menyusui. Menyusui akan menekan siklus menstruasi, menyusui dapat menyebabkan perubahan sel payudara yang membuat sel wanita lebih tahan terhadap mutasi sel terkait kanker (Priyatin, 2013).

Waktu menyusui yang lebih lama mempunyai efek yang posistif dalam menurunkan risiko kanker payudara dimana terjadi penurunan kadar hormon estrogen dan pengeluaran bahan-bahan pemicu kanker selama proses menyusui, semakin lama waktu menyusui semakin besar efek perlindungan terhadap kanker payudara yang ada. Oleh karena itu risiko kanker payudara akan menurun jika perempuan sering menyusui dan dalam jangka waktu yang lama atau 2 tahun.

Simpulan, semakin sedikit waktu dalam menyusui anak maka semakin besar risiko terkena kanker payudara.

\section{Ucapan Terima Kasih}

Penelitian ini didanai oleh DIKTI, terima kasih atas dibiayainya penelitian ini. Terima kasih juga kepada tenaga kesehatan yang bertugas di poli bedah dan tenaga medical record yang telah membantu selama pengambilan data, dan memberikan data pasien kanker yang sedang menjalani pengobatan.

\section{DAFTAR PUSTAKA}

Abidin, 2014 “ Faktor Risiko Kejadian Kanker Payudara di RSUD Labuang Baji Makassar" Jurnal Ilmiah Kesehatan Diagnosis Vol 4 no 2.
Alimul, A. 2007.Metode Penelitian Kebidanan Teknik Analisa Data. Jakarta : Salemba Medika.

Budiningsih, et al, 2005, " Epidemiological Analysis of Risk Factors For breast cancer in Indonesia Females" Jurnal Med.J. Indonesia.

Bode, A.M. \& Dong, Z., 2009. Cancer prevention research - then and now. Nature reviews. Cancer, 9(7), pp.508-16. Available at: http://www.pubmedcentral.nih.gov/a rticlerender.fcgi?artid=2838238\&too $\mathrm{l}=$ pmcentrez\&rendertype $=\mathrm{abstract}$ [Accessed April 14, 2017].

Bustan, M.N., 2007. Epidemiologi Penyakit Tidak Menular, Jakarta: Rineka Cipta.

Fitoni, Hendri, 2012," Faktor Risiko Kanker Payudara di RSUD DR, Soedarso Pontianak" Universitas Tanjungpura-Tesis

Genis, G.W 2005, Kegemukan dan obesitas, Bandung: Unpad.

Indrati, Rini 2005," Faktor Risiko yang Berpengaruh terhadap Ca Payudara Wanita di RS DR. Kariadi Semarang" Undip-Tesis

Komalasari, Renata, 2009, Buku Saku kebidanan, Jakarta, EGC

Kartikawati, E., 2013. Awas!!! Bahaya Kanker Payudara \& Kanker Serviks B. Baru, ed., Bandung.

Lertkhachonsuk, A.-A. et al., 2013. Cancer prevention in Asia: resourcestratified guidelines from the Asian Oncology Summit 2013. The lancet oncology, 14(12), pp.e497-507. Available at: http://www.ncbi.nlm.nih.gov/pubme d/24176569 [Accessed April 14, 2017].

L.Anggorowati, 2010," Faktor Risiko Kanker Payudara di RSUD Kudus" Jurnal Kesmas

Lincoln, J dan Wilensky 2008, Kanker payudara diagnosis dan solusinya, Jakarta: 1Prestasi Pustakaraya.

Noor, N.N., 2008. Epidemiologi, Jakarta: Reineka Cipta. 
Noto1atmodjo, S., 2014. Ilmu Perilaku Kesehatan Cetakan Ke., Jakarta: Rineka Cipta.

Notoadmodjo, Soekidjo. 2010. Pendidikan dan Prilaku Kesehatan. Jakarta : RinekaCipta.

Priyatin, Cici, 2013, “ Faktor Risiko yang Berpengaruh terhadap Kejadian Kanker Payudara di RSUP DR. Kariadi Semarang" Jurnal Kebidanan Vol 2 No 5. ISSN 20897669.

Rasjidi, 2009, Pencegahan Kanker Pada Wanita, Sagung-Seto, Jakarta

Rosfein, R 2012, Jurnal faktor-faktor yang berhubungan dengan terjadinya kanker payudara pada beberapa wanita di Rumah Sakit Jakarta,
Jakarta: Cermin Dunia Kedokteran, No.75, ISSN 0125-913X.

Riskesdas Data 2007

Satmoko, B., 2009. Buku Pintar Kanker, Yogyakarta: Powerbooks.

Shadine, M., 2012. Penyakit Wanita Pencegahan, Deteksi Dini, dan Pengobatannya, Yogyakarta: Citra Pustaka.

Soebachman, A., 2011. Awas 7 Kanker Paling Mematikan, Yogyakarta: Syura Media Utama.

Supriyanto, W., 2017. Kanker Deteksi Dini, Pengobatan dan Penyembuhannya, Yogyakarta: Parama Ilmu.

Wiknjosastro, H 2005, Ilmu kandunan, Jakarta: Yayasan Bina P 